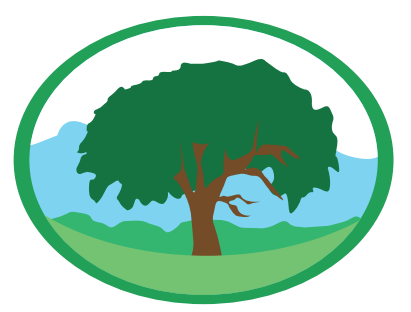

\title{
GESTÃO AMBIENTAL APLICADA EM UMA EMPRESA CALC̣ADISTA NO SUL DO BRASIL (RIO GRANDE DO SUL)
}

PORN, C. M. ${ }^{1}$; PRESTES, M. M. B. ${ }^{2}$; BOHRER, R. E. G. ${ }^{3}$; LARA, D. M. ${ }^{4}$.

${ }^{1}$ Acadêmica do Curso de Bacharelado em Gestão Ambiental na Universidade Estadual do Rio Grande do Sul (UERGS), Unidade Alto da Serra do Botucaraí Soledade/RS. candice-pornQuergs.edu.br

${ }^{2}$ Bióloga, Professora Doutora na Universidade Estadual do Rio Grande do Sul (UERGS), Unidade Alto da Serra do Botucaraí Soledade/ RS. marta-barbosaquergs.edu.br

${ }^{3}$ Engenheiro Ambiental, Professor Doutor na Universidade Estadual do Rio Grande do Sul (UERGS), Unidade em Três Passos/RS. robson-bohrerduergs.edu.br

${ }^{4}$ Engenheira Ambiental, Professora Doutora na Universidade Estadual do Rio Grande do Sul (UERGS), Unidade Alto da Serra do Botucaraí em Soledade/RS. daniela-laraQuergs.edu.br

Palavras-chave: empresarial, responsabilidade, planejamento.

\begin{abstract}
Resumo
Atualmente as empresas têm presenciado o surgimento de novos papéis a serem por elas desempenhados, limitados não somente ao âmbito econômico, mas também em uma atuação responsável na questão socioambiental. Observa-se também que grandes empresas, com intuito de redução de custos, terceirizam alguns de seus processos. Ao terceirizar a mão de obra, a produção e os custos das atividades, terceirizam também a gestão dos resíduos e dos rejeitos. Tal fato se torna agravante se houver desconhecimento sobre a toxicidade dos resíduos gerados. Neste sentido, o estudo objetiva caracterizar o processo produtivo de uma indústria do setor calçadista e propor melhorias quanto ao gerenciamento dos resíduos. Utilizou-se como metodologia a pesquisa bibliográfica e a pesquisa-ação, uma vez que houveram contribuições de melhoramento contínuo e a integração entre o objeto de estudo e os objetivos da pesquisa. Os resultados através do mapeamento do processo produtivo industrial possibilitaram uma visão sistêmica das atividades desenvolvidas e as proposições de melhorias quanto a gestão ambiental, atendimento a legislação e a segurança foram aceitas com contento pelo empreendedor.
\end{abstract}

\section{ENVIRONMENTAL MANAGEMENT APPLIED ON A FOOTWEAR COMPANY IN THE SOUTH OF BRAZIL (RIO GRANDE DO SUL]}

Keywords:

responsibility,

\section{business, Abstract}

planning. Now a days the companies have noticed the beginning of new roles to be developed by them, limited not only to the economic scope, but also to a responsible performance on the social environmental issue. It is also observed that big companies, with the intention of cost reduction, outsource some of their processes. Outsourcing the workforce, the production and the activities costs, they also outsource the waste management. This fact becomes aggravating if there is any unfamiliarity about the toxicity of the generated waste. On this sense, the study aims to characterize the productive process of a footwear company and propose an improvement on the waste management. It was used as a methodology the bibliographical research and the action-research, once there were continuous increasing contributions and the integration between the study object and the goals of the research. The results through the mapping of the industrial productive process enabled a systemic vision of the developed activities and the proposition of improvement to the environmental management, compliance with legislation and security were happily accepted by the entrepreneur. 


\section{INTRODUCุÃo}

Recentemente a gestão empresarial tem passado por mudanças significativas no âmbito social, econômico e ambiental, consequentemente, existe uma necessidade urgente de busca de novos conhecimentos e parcerias. Somente o atendimento das perguntas: o que produzir, como produzir e para quem produzir não são suficientes para a garantia financeira dos empreendimentos (VIEIRA, 2011). Segundo SCHULTZ (2016) a empresa deveria reconhecer que sua responsabilidade para com a sociedade e público em geral vai muito além de suas responsabilidades com seus clientes.

Entre os grandes desafios encontrados, destaca-se o gerenciamento dos resíduos, em especial para este estudo no setor calçadista (VIEGAS, FRACASSO, 1998; LEITE, 2006 e PEREIRA et al., 2012). Estes resíduos possuem predominantemente características químicas com grande potencial poluidor e, neste sentido, muitas empresas não estão preparadas e preocupadas com o tratamento e disposição ambientalmente adequado dos mesmos (OLIVEIRA, MATOS, CASTRO, 2017). Uma quantidade destes resíduos é encaminhada para aterros, e se esses não estão adequados às condições de segurança ambiental previstas na legislação, poderão acarretar em danos como a contaminação dos lençóis freáticos e recursos hídricos ocasionados pela lixiviação de seus componentes (ELK, 2007).

Neste sentido, o planejamento socioambiental para indústria calçadista necessita abordar as características do setor com a potencialização de políticas com caráter estratégico de açóes para superar os problemas de comercialização internos e externos e, sobretudo, garantir a equivalência entre a qualidade do produto e o desenvolvimento sustentável (PLENTZ, TOCCHETTO, 2014).

Tal processo se baseia desde o início da escolha do design e sua modelagem, corte, costura e pesponto, montagem, solado e acabamento final (LINS, 2007; LOPES, 2014; JÚNIOR, SANTOS, 2017; BIERMANN, 2007; VIEIRA, BARBOSA, 2011 e ZORN, 2007). Este processo segue diversas etapas, para a produção do calçado, sendo que empresas maiores terceirizam sua mão de obra para pequenos ateliers, pois, realizam apenas o acabamento da montagem do produto (COSTA et al., 2008; CAMPO, 2018 e
GIANNETTI et al., 2001).

A empresa do setor calçadista localiza-se no município de Bom Retiro do Sul/RS conforme apresentado na Figura 2. A empresa atua no mercado desde 21 de janeiro de 2015, quando começou suas atividades em uma pequena construçáo no recinto familiar com 12 colaboradores e prestando serviços para as empresas do seu município.

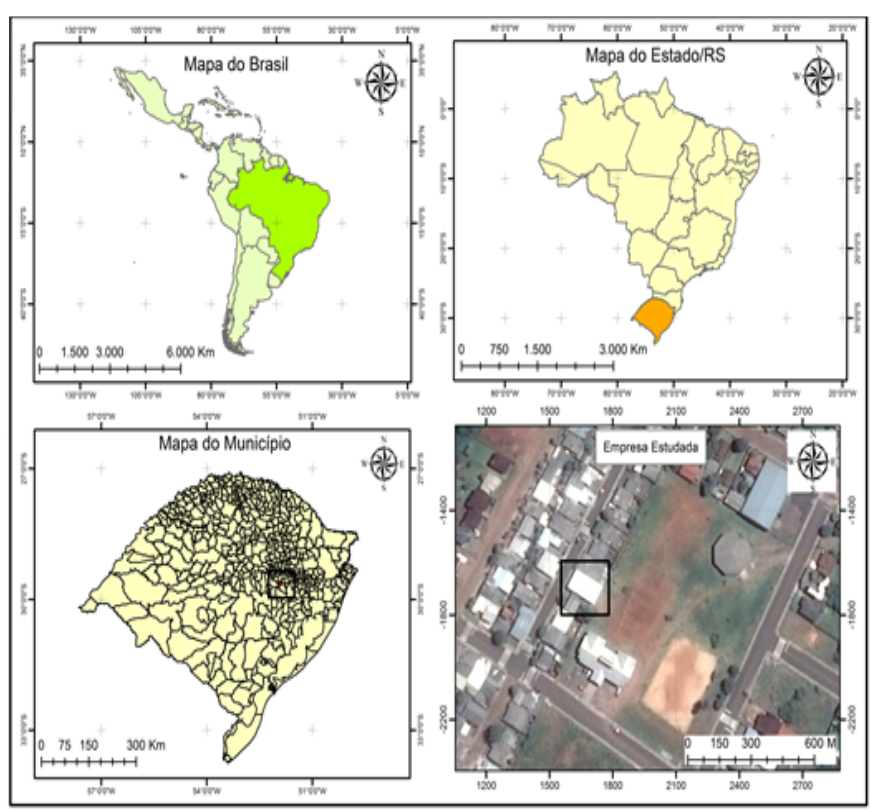

Figura 1. Mapa da localização da empresa em Bom Retiro do Sul/RS.

Atualmente a empresa trabalha de forma terceirizada no ramo de atividade de confecção da pré-forração da palmilha para uma grande indústria do setor calçadista. A empresa emprega 26 colaboradores e possui uma produção diária de 5.000 pares de palmilhas por dia.

Diante do exposto, este estudo objetiva caracterizar o processo produtivo de uma indústria de pequeno porte do setor calçadista e propor melhorias quanto ao correto gerenciamento dos resíduos, ao atendimento das normas de segurança do trabalho e açóes relacionadas às práticas de gestão ambiental para atendimento à legislação vigente.

\section{MATERIAL E MÉTODOS}

Para a realização deste estudo foi utilizada como metodologia a pesquisa bibliográfica e a pesquisaação. A pesquisa bibliográfica foi fundamental para 
aprimoramento do objeto de estudo, pois procurou-se explicar um problema a partir de referências teóricas que se encontram publicadas. Já a pesquisa-ação permitiu o melhoramento contínuo e a integração entre o objeto de estudo e os objetivos da pesquisa (THIOLLENT (1997) e BARBIER (2002), uma vez que se propóe a dizer de que modo ou por que causas o fenômeno estudado é produzido. Baseado nisto, optou-se por estudar as variáveis relacionadas com o objeto de estudo (MARTINS, 2000).

A sequência metodológica está ilustrada no fluxograma executivo proposto para o estudo (Figura 1).

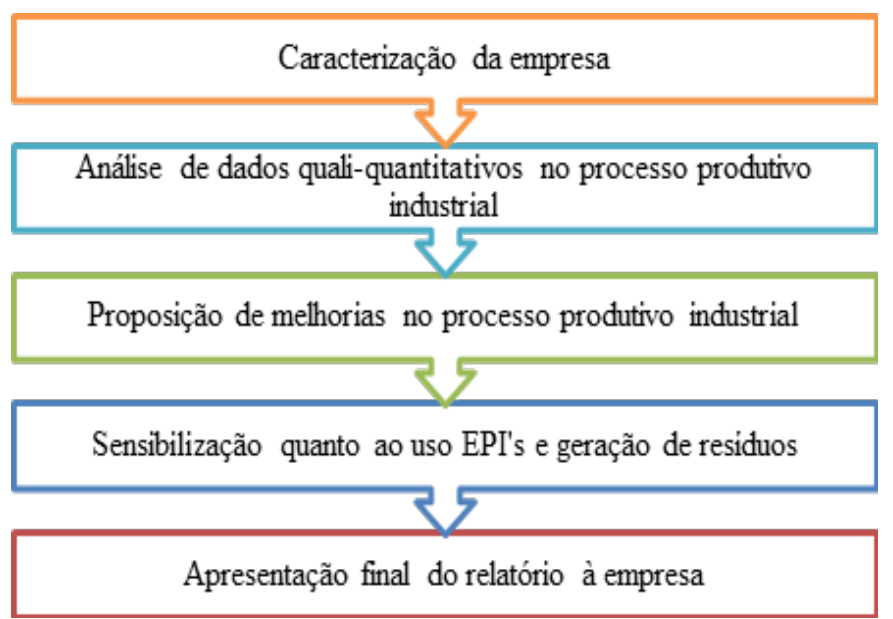

Figura 2. Fluxograma executivo das etapas do trabalho.

Após o embasamento teórico, realizou-se a visitação na indústria de calçados localizada no município de Bom Retiro do Sul/RS. Na oportunidade da visita, o empresário contou brevemente o histórico do empreendimento, passando o conhecimento adquirido a respeito da empresa e contando como foi o surgimento e as evoluçóes que a empresa obteve até os dias atuais. Após isso, explanou sobre o funcionamento do processo produtivo industrial calçadista e abordou algumas melhorias já aplicadas na empresa.

Realizou-se o levantamento dos dados qualiquantitativos, bem como análises das planilhas de controle fornecidas pela empresa. As mesmas foram avaliadas através das anotaçóes geradas no processo produtivo industrial, em especial, na descrição das atividades, na geração de resíduos e no atendimento à legislação vigente.

Através da caracterização do processo produtivo industrial foram realizadas proposiçóes de melhorias na empresa. Com base na caracterização do Processo Produtivo Industrial (PPI), foram propostos temas para treinamentos dos colaboradores quanto ao correto uso de Equipamentos de Proteção Individual (EPI's). Ainda, em função da importância do uso de EPI's, foi concomitantemente abordado nos treinamentos, os exemplos da importância de práticas seguras para a execução das suas atividades na empresa.

Ainda as questôes legais foram avaliadas quanto ao atendimento e após a execução das atividades propostas na metodologia, a empresa recebeu um relatório dos resultados obtidos com este estudo.

\section{RESULTADOS E DISCUSSÃO}

\section{Caracterização do Processo Produtivo Industrial}

A empresa recebe os materiais da fornecedora/ matriz todos os dias pela manhã e possui metas diárias para a confecção do principal produto produzido (palmilha). A Figura 3 apresenta o modelo da préforração da palmilha (Figura 3).

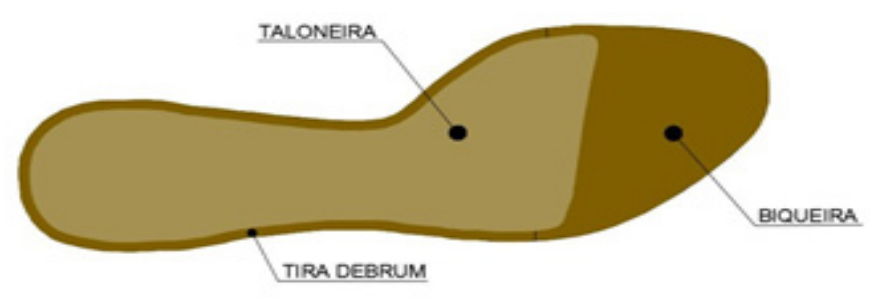

Figura 3. Demonstração do modelo da palmilha.

As Figuras 4 e 5 detalham as etapas necessárias para a confecção da pré-forração da palmilha e as principais atividades estão destacadas nos fluxogramas.

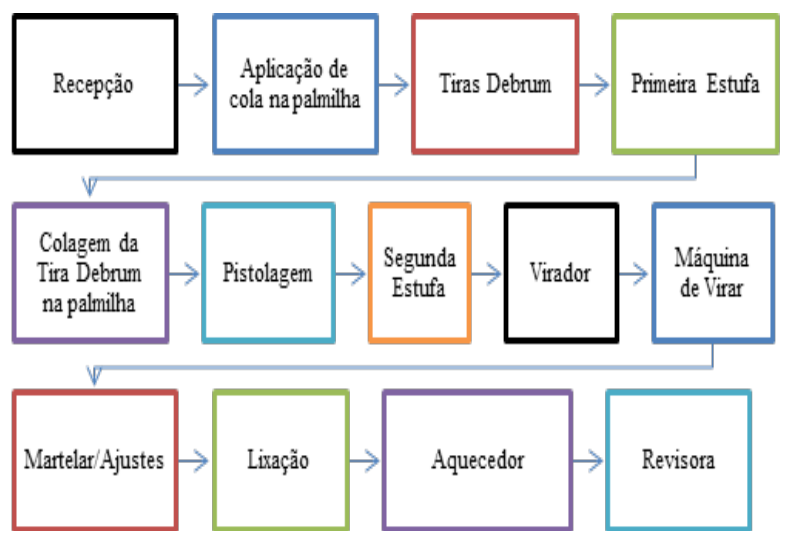

Figura 4. Fluxograma da pré-forração da palmilha na primeira esteira. 


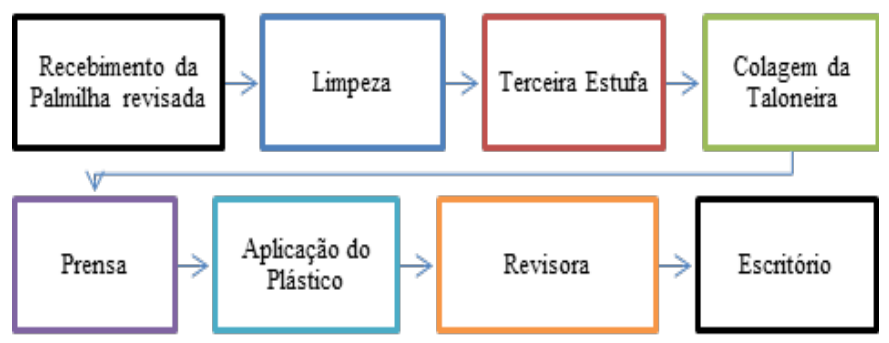

Figura 5. Fluxograma da pré-forração da palmilha na segunda esteira.

A recepção dos materiais é importante, pois se mal executada, acarretará problemas operacionais e atraso na produção. Ao término da verificação do recebimento dos materiais, os mesmos são encaminhados para as esteiras. Na primeira esteira, é realizada a forração do debrum e biqueira ao redor da palmilha. Já na segunda esteira, o processo contempla o acabamento com colagem da taloneira na parte superior da palmilha. Sáo realizados aproximadamente 500 pares por hora, tanto na primeira esteira como na segunda esteira.

A colagem da palmilha é a etapa posterior à forração com o debrum. Aplica-se a cola e depois dispóem novamente as palmilhas na esteira. A cola tem a finalidade de fixar as borrachas vulcanizadas, couro solado, couro cabedal, látex vulcanizado e palmilhas. Os resíduos de embalagens da cola ficam armazenados em um depósito temporariamente na empresa e depois são encaminhados novamente para a empresa matriz.

Passado a cola nas palmilhas, a próxima etapa é a separação das tiras debrum em três caixas, sendo que as mesmas são separadas por numeração. $\mathrm{O}$ colaborador passa cola utilizando um adesivo com solvente orgânico para limpeza de materiais e também para diluição da cola. O resíduo químico, após a realização deste estudo passou a ser enviado para a empresa matriz. A próxima etapa, pós a passagem da cola na tira debrum, o produto segue para a estufa. Esta etapa é importante para que aconteça a fixação da fita na palmilha. A temperatura de aquecimento varia entre $60^{\circ}$ a $70^{\circ} \mathrm{C}$. $O$ risco físico apresenta nesta etapa é minimizado com o EPI's adequados. A Figura 6 apresenta esta etapa do processo descrita.

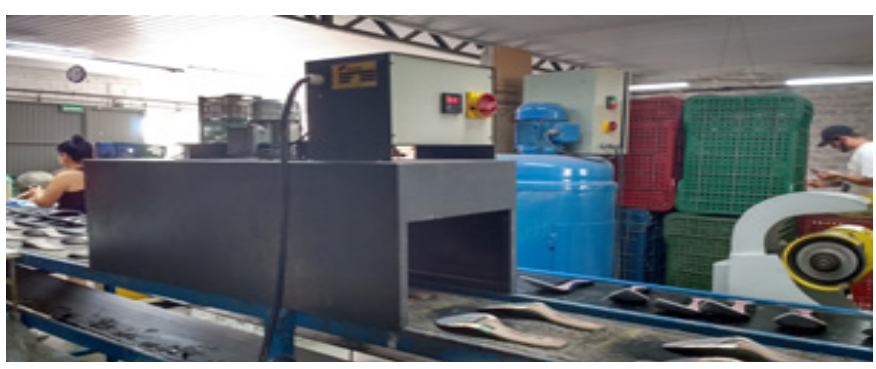

Figura 6. Secagem da tira debrum na estufa de aquecimento.

Após passar pela estufa, realiza-se a colagem da tira debrum ao redor da palmilha. Esta colagem é realizada por dois colaboradores, uma vez que é necessária rapidez para evitar que a temperatura fique abaixo do recomendado para o processo de colagem deste material.

Ao finalizar a colagem das tiras debrum, realiza-se a colagem na ponta da palmilha e, posteriormente, o produto deverá ser encaminhado para a máquina de virar corte e/ou costura de passar cola. A cola utilizada nesta etapa tem a finalidade de limpeza dos materiais. FELL (2017) salienta que a máquina de passar cola deve possuir um par de rolos com pressáo ajustada por mola, pois o rolo de baixo deverá ficar em contato com a cola líquida na parte inferior. Isto resultará, a aplicação do adesivo nas tiras e peças de calçado de forma contínua.

As características da cola podem causar irritação na pele, vias respiratórias, olhos, dores de cabeça aos colaboradores (AMAZONAS, 2010). Neste sentido, é importante a adequação com sistema de exaustão nesta atividade do processo, e principalmente a utilização de máscaras e luvas, itens repassados pela empresa.

A máquina de passar cola presente na empresa encontra-se dentro das especificaçóes propostas pelas normas da Associação Brasileira das Indústrias de Máquinas e Equipamentos ABRAMEQ, Serviço Brasileiro de Apoio às Micro e Pequenas Empresas - SEBRAE-RS, pela Cartilha de Segurança em Máquinas e Equipamentos para Calçados - Requisitos Mínimos de Segurança, Norma Regulamentadora No 12 do Ministério do Trabalho.

Feito a aplicação da cola nas pontas das biqueiras, o produto é encaminhado para a segunda estufa. $\mathrm{O}$ objetivo deste processo é reativar a cola do processo 
anterior e a temperatura para a reativação é entre $60^{\circ}$ a $70^{\circ} \mathrm{C}$. Ao passar pela estufa que reativará a cola, o produto segue para a etapa onde o calçado é virado do avesso para a realização da colagem das pontas das biqueiras na sola da palmilha.

Após a colagem das pontas das biqueiras, a palmilha é encaminhada para a máquina de virar corte. Esta máquina possui um compartilhamento onde é colocada a cola em forma de grânulos. Assim, após o processo de aquecimento (aproximadamente $140^{\circ} \mathrm{C}$ ) da cola, a mesma torna-se líquida e é aplicada ao redor da palmilha. Após a aplicação da cola quente é realizada o martelamento da palmilha (processo manual, somente utilizado para ajustar a palmilha ao forro). Este processo é realizado para retirar excesso de enrugamento do produto causado pela cola. Para a atividade, os colaboradores recebem a instrução em relação aos cuidados ergonômicos.

O lixamento é a próxima etapa do processo. A atividade é realizada através da máquina escova lixadeira. Gera-se aproximadamente $10 \mathrm{Kg}$ de resíduos (pó) por mês e este rejeito é armazenado e encaminhado à empresa matriz.

A lixadeira possui o coletor para recolhimento do pó gerado no processo de produção, pois a ausência do mesmo prejudica o funcionamento das máquinas rotativas e, consequentemente, reduz a vida útil dos rolamentos. Esta máquina também possui proteçóes mecânicas para prevenir o contato acidental do operador nas partes rotativas. Esta máquina está adequada de acordo com a Norma Regulamentadora No 12.

O colaborador quando em contato prolongado com o pó, fica sujeito a problemas respiratórios (asma e bronquite, por exemplo) e devem usar obrigatoriamente máscaras protetoras, principalmente, quem já sofre de problemas respiratórios (LUZ et al., 2013).

Este pó de couro curtido e/ou outros materiais alternativos causam impactos ambientais e aos colaboradores. Se porventura este material for descartado incorretamente, poderá acarretar impactos no solo, na água e entre outros ambientes (CALANDRO, CAMPOS, 2015).

Em função do exposto, este resíduo é coletado e armazenado em saco plástico fornecido pela empresa (mais resistente que os sacos plásticos convencionais) e destinado para a empresa matriz. Posteriormente, ao receber os materiais, a empresa matriz encaminha uma vez por semana seus resíduos aos aterros sanitários.

Realiza-se logo após a etapa do lixamento, o aquecimento da palmilha e a conferência dos pares. A palmilha é aquecida em equipamento comumente denominado de chapa quente. A conferência de pares é uma etapa muito importante no processo, pois sáo identificadas as falhas e deformidades apresentadas no processo de fabricação do produto.

Já na esteira 2, depois da conferência dos talóes e das palmilhas, um colaborador coloca a palmilha, a espuma, a taloneira e a etiqueta pronta sobre a esteira. Neste momento é realizada a conferência dos números das taloneiras para a colagem correta do processo da palmilha.

Nesta etapa do processo, a limpeza do debrum e da biqueira desempenham um papel fundamental para que haja um boa aderência e colagem do material. Se o processo não for realizado de forma eficiente, ocasionará problemas futuros no sapato, pois soltará a sola. Os resíduos gerados são encaminhados para a empresa matriz.

Com a limpeza realizada nas biqueiras e nas tiras debrum, a palmilha é novamente encaminhada para a estufa de aquecimento. A temperatura de aquecimento é regulada entre 60 a $70{ }^{\circ} \mathrm{C}$ e objetiva a reativação da cola da palmilha. Após a reativaçáo da cola e posterior fixação da tira na palmilha, a etapa seguinte é a colagem das taloneiras. Esta etapa é realizada na máquina de prensagem.

A finalidade desta etapa é a fixação da taloneiras na palmilha e, para isto, a temperatura recomendada deve ficar entre $60^{\circ}$ a $70^{\circ} \mathrm{C}$. A máquina de prensagem hoje é um gargalo no processo produtivo da empresa, pois somente pode-se prensar uma palminha de cada vez. Estima-se a produçáo por hora de 500 peças. Toda a máquina foi adequada para atendimento a NR 12 e o seu acionamento é bimanual.

Um detalhe importante no processo de produção da palmilha é a colocação de um plástico entre palmilha com a taloneira. O plástico serve para que não aconteça a colagem da taloneira com a palmilha, pois, se isto acontecer, o processo de produção do sapato na 
empresa matriz sofrerá atrasos e, consequentemente, terá perdas de produtividade.

Após realização da aplicação do plástico entre palmilha com a taloneira, realiza-se a conferência e revisão das palmilhas de acordo com a solicitação dos talóes. Os produtos prontos ficam organizados em caixas e/ou plásticos para que posteriormente seja emitida a nota fiscal.

A empresa atende as legislaçóes pertinentes quanto aos seus resíduos que são gerados, tais como: a Lei Nacional no 11.211/2005 dispóe sobre as condiçóes exigíveis para a identificação do couro e das matérias primas sucedâneas, utilizados na confecçáo de calçados e artefatos. A mesma lei ainda inclui os produtos químicos e materiais que são utilizados, bem como a fabricação para a exportação do calçado.

Atendendo também a Lei Municipal no 3.516/2009 institui as microempresas, empresas de pequeno porte e microempreendedor individual. A mesma ajuda aos incentivos de fiscalizaçóes, ao processo de registro, a simplificação aos aspectos ambientais de controle. $\mathrm{O}$ alvará de funcionamento provisório da empresa calçadista permite o início de operação do estabelecimento e atendimento a Lei Complementar Federal 128/08 (Lei 3.516, 2009).

A empresa conta com laudos técnicos deaterramento, energia elétrica e adequação de seus equipamentos no setor do processo produtivo industrial. Anteriormente a empresa náo possuía esses laudos e com o tempo o empreendedor começou a colocar em prática estas adaptaçóes para que seu empreendimento atendesse as normas vigentes.

Por exemplo, pode-se citar a NR-12, uma das principais normas de segurança de máquinas que teve seu atendimento de forma íntegra pela empresa. Esta norma define os princípios e medidas de proteção e prevenção contra riscos de acidentes na operação de máquinas. As máquinas, de acordo com a NR - 12 devem possuir equipamentos de bloqueios/paradas de emergências, intertravamentos elétricos e/ou mecânicos. Também precisam ter partes rotativas protegidas para garantir a segurança do colaborador.

Diante das legislaçóes, a empresa contratou uma equipe terceira para auxiliar no atendimento quanto à segurança quanto às instalaçôes de energia elétrica e aterramento, além de iniciar o processo de gestáo ambiental juntamente com o desenvolvimento deste trabalho.

Tratando-se de consumos a empresa não possui controles e metas em relação ao consumo de energia e água. Ao analisar o consumo de energia elétrica, percebe-se um gradativo aumento no período de janeiro de 2017 a dezembro 2018 com uma média mensal de $\mathrm{R} \$ 1.855,06$, atenuando mais significativamente nos meses de outubro e novembro de 2017. Nestes meses, a empresa teve que ampliar a sua jornada de trabalho para 5.000 pares de palmilha/dia. Já o mês de fevereiro de 2017 justifica-se o baixo consumo por ser um período de oscilação do processo produtivo industrial. Mesmo fato pode ser observado no mês de janeiro, fevereiro e março de 2018.

$\mathrm{O}$ valor médio gasto no consumo de água foi de R\$ 111,75 para intervalo de meses avaliados. A mensuração e controle dos recursos gastos com água e energia objetivam mostrar para o empreendedor a importância de um monitoramento dos custos dentro do processo de produção. Futuramente pretende-se desenvolver novos indicadores para auxiliar na gestão da empresa.

Os extintores foram adquiridos pela empresa objetivando atender a norma vigente e assegurar segurança e rápida ação, caso aconteça algum incidente no empreendimento. Da mesma forma como citado quanto ao uso de EPI's, a empresa realiza periodicamente treinamentos com os colaboradores quanto ao uso e também ao correto manuseio dos equipamentos de incêndio. Contudo, ainda restam algumas melhorias a serem feitas, como por exemplo, a pintura no chão onde está localizado o extintor com as cores corretas de sua sinalização (amarelo e vermelho) para atendimento a NR 26.

Além dos resíduos gerados no processo produtivo industrial, outros resíduos são gerados na empresa, tais como: papelão, pó de lixação, restos de palmilhas, tiras, biqueiras, pano de limpeza da palmilha, latas de cola e rejeitos provenientes dos banheiros. Contribuiçóes para melhor organização e segregação dos resíduos foram repassados ao empreendedor, tais como o armazenamento e posterior venda dos materiais passíveis de comercialização. Além disto, os resíduos 
do pó da lixação, restos de palmilhas, tiras, pano de limpeza da palmilha, colas e biqueiras são recolhidos mensalmente através da emissão de nota fiscal e retornados ao seu fornecedor.

Durante o processo produtivo a empresa realiza alguns cortes da parte das tiras debrum que sobra ao redor do calçado, sendo que, essas tiras são cortadas aproximadamente $3 \mathrm{~cm}$ e após estas sobras são descartadas e enviadas novamente para a empresa. Apesar deste material apresentar um pouco de sobra para eventuais erros, aconselha-se que seja realizado um redimensionamento de tamanho com o intuito de reduzir a perda de material. O redimensionamento dos materiais somente é realizado na empresa matriz que fornece as tiras, cabendo somente ao fornecedor buscar medidas de redução do material.

Quanto à geração da cola, o empreendedor tem o controle por meio das notas fiscais. Portanto, o responsável deste setor encomenda as quantidades de colas para uso semanal e diante desta encomenda, é emitida a nota fiscal com a quantia e quais colas serão enviadas para a empresa terceira e, posteriormente, devolvida para a empresa matriz.

Com intuito de melhorar o processo de treinamento de cada colaborador contratado na empresa, foi proposto ao empreendedor a descrição de todas as atividades levando em consideração os itens de segurança e ambientais para executá-las. Para isto, está sendo elaborado um Procedimento Operacional Padrão - POP. O modelo ainda está em elaboração, pois a empresa quer propor a execução do documento que seja feito por cada colaborador responsável pelo posto de trabalho.

Muitas contribuiçôes foram recebidas com entusiasmo pelo empreendedor e foram (e serão) aplicadas tendo como base este trabalho realizado. $\mathrm{O}$ mapeamento do processo, o controle de energia, o consumo de água, a geração de resíduos e adequação às normas vigentes relacionadas à segurança e à saúde do colaborador, trazem parâmetros até então não mensurados e quantificados no custo do produto pelo empreendedor. Cabe ainda salientar os treinamentos que foram e serão oportunizados após a realização deste trabalho.

\section{CONCLUSÃO}

O empreendimento, objeto de estudo neste trabalho, vem adequando-se para fabricar produtos com qualidade, evitar perdas financeiras e, ainda, desafiar-se como uma empresa de pequeno porte e que se preocupa com os impactos ambientais gerados, além de almejar possuir uma produçáo enxuta.

Os resultados através do mapeamento do processo produtivo industrial possibilitaram uma visão sistêmica das atividades desenvolvidas e as proposiçóes de melhorias quanto a gestão de ambiental, atendimento a legislaçáo e a segurança foram aceitas com contento pelo empreendedor.

\section{LITERATURA CITADA}

AMAZONAS. Ficha de Informaçóes de Segurança de produtos químicos - FISPQ, Produto: AT-939. 19 ago. 2015.

BIERMANN, M. J. E. Gestâo do processo produtivo. $1^{\circ} \mathrm{Ed}$. Porto Alegre: SEBRAE/RS, 2007.

CALANDRO, M. L. CAMPOS, S. H. Arranjo Produtivo Local (APL) Calçadista Sinos-Paranhana - RS: análise do segmento de calçados de alto valor agregado. Relatório II. Porto Alegre. Fundação de Economia e Estatística - FEE, 2015.

CAMPOS, André Gambier. Terceirização do trabalho no Brasil: novas e distintas perspectivas para o debate. Instituto de Pesquisa Econômica Aplicada - IPEA. Brasília. 2018. Disponível em: <http://repositorio.ipea.gov.br/bitstream/11058/8258/1/ Terceiriza\%C3\%A7\%C3\%A3o\%20do\%20trabalho\%20no\%20 Brasil_novas $\% 20 \mathrm{e} \% 20$ distintas $\% 20$ perspectivas $\% 20$ para $\% 20$ o\%20debate.pdf>. Acesso em: 10 Nov. 2018.

COSTA, Achyles Barcelos da. et al. Transformaçôes no Processo de Trabalho na Indústria de Calçados do Vale do Sinos. Revista Associação Brasileira de Estdos do Trabalho - ABET. Vol. VII, no2. 2008. Disponível em: <http://periodicos.ufpb.br/index. php/abet/article/download/15233/8624>. Acesso em: 10 Nov. 2018.

ELK, Ana Ghislane Henriques Pereira Van. Redução de emissóes na disposiçáo final. Coordenação de Karin Segala - Rio de Janeiro: IBAM, 2007. Disponível em: <http:// www.mma.gov.br/estruturas/srhu_urbano/_publicacao/125_ publicacao12032009023918.pdf>. Acesso em: 23 Out. 2018.

FELL, Cristiano. Laudo da Máquina Passar Cola - No Patrimônio 007 e 015. Responsável Técnico. Estrela - RS. 03.07.2017.

GIANNETTI, Biagio. Fernando. et al. O Nosso Cromo de cada dia: Benefícios e Riscos. Revista de Graduação da Engenharia Química, Ano IV, 2001.

JÚNIOR, Tadeu Artur de Melo. SANTOS, Cristina dos. Materiais e processo de produção de solados: destinação final de resíduos em empresas calçadistas no município de FrancaSP. Revista Eletrônica "Diálogos Acadêmicos”. Jan/Jul, 2017. Disponível em: <http://uniesp.edu.br/sites/_biblioteca/ revistas/20180502083940.pdf>. Acesso em: 10 Nov. 2018.

Lei $n^{\circ} 11.211 / 2005$. Dispóe sobre as condiçóes exigíveis para a identificação do couro e das matérias-primas sucedâneas, 
a identificação do couro e das matérias-primas sucedâneas, utilizados na confecção de calçados e artefatos. Presidência da República. Disponível em: < http://www.planalto.gov.br/ ccivil_03/_ato2004-2006/2005/lei/111211.htm>. Acesso em: 08 abr. 2018.

Lei no 3.516/2009. Institui a Lei Geral Municipal da Microempresa, Empresa de Pequeno Porte e Microempreendedor Individual, e dá outras providências. Munícipio de Bom Retiro do Sul/RS. 18 nov. 2009. Disponível em: < file:///D:/Meus\%20 Documentos/Downloads/LM-3.516-2009-Bom-Retiro-do-SulRS.pdf.pdf>. Acesso em: 08 abr. 2018.

LEITE, P. R. Logística reversa, meio ambiente e competitividade. 2. ed. São Paulo: Pearson. Prentice Hall, 2006.

LINS, Gabriel Estellita. Perfil da indústria de calçados: 03 processos internos. Sebrae Nacional. 2007.

LOPES, Herton Castiglioni. O setor calçadista do vale dos sinos/RS: um estudo a partir do modelo estrutura-condutadesempenho. Revista de Economia. V.40. n3. Editora UFPR. Set/ Dez. 2014. Disponível em: <https://revistas.ufpr.br/economia/ article/download/40610/27859>. Acesso em: 10 Nov. 2018.

LUZ, Fernanda Reinher da. et al. Riscos ocupacionais de uma indústria calçadista sob a ótica dos trabalhadores. Revista Brasileira de Enfermagem - REBEn, Brasília, jan-fev. 2013. Disponível em: <http://www.scielo.br/pdf/reben/v66n1/v66n1a10.pdf>. Acesso em: 5 set. 2018.

NR 12. Segurança do Trabalho em Máquinas e Equipamentos. Disponível em: <http://www.trabalho.gov.br/images// Documentos/SST/NR/NR12/NR-12.pdf>. Acesso em: 17 mar. 2018.

NR 26. Sinalização de Segurança. Disponível em: <http://www. trabalho.gov.br/images/Documentos/SST/NR/NR26.pdf>. Acesso em: 19 mar. 2018.

MARTINS, Gilberto de Andrade. Manual para elaboração de monografias e dissertaçóes. São Paulo: Atlas, 2000.

OLIVEIRA, E. de. J. MATOS, G. de. F. M. CASTRO, D. S. P. de. Gestão ambiental e responsabilidade social corporativa: estratégias de negócio focadas na realidade brasileira. Revista Gestão e Desenvolvimento. v. 14 | n. 2 | p. 155-157 | jul/dez. 2017.

PEREIRA, A. L. et al. Logística reversa e sustentabilidade. São Paulo: Cengage Learning, 2012.

PLENTZ, Natália Debeluck. TOCCHETTO, Marta Lopes. O Ecodesign na Indústria de Calçados: proposta para um mercado em transformação. Revista Eletrônica em Gestão, Educação e Tecnologia Ambiental - REGET. Revista do Centro do Ciências Naturais e Exatas - UFSM, Santa Maria. Set/Dez. 2014.

SCHULTZ, Glauco. Introdução à gestão de organizaçôes. Porto Alegre: Editora da UFRGS, 2016. Disponível em: <http://www. ufrgs.br/cursopgdr/downloadsSerie/derad103.pdf>. Acesso em: 23 Out. 2018.

THIOLLENT, M. Metodologia da Pesquisa-Ação. 6o Ed. São Paulo, SP: Cortez, 1997.

ZORN, Gerson. Processo de Fabricação do calçado. Serviço Nacional de Aprendizagem Industrial (SENAI) - RS. Centro Tecnológico do Calçado. Serviço Brasileiro de Respostas Técnicas - SBRT. Porto Alegre. 2007.

VIEGAS, Cláudia. FRACASSO, Edi Madalena. Capacidade tecnológica e gestão de resíduos em empresas de calçados do vale dos sinos: estudo de dois casos. Revista de Administração Contemporânea. V.2. Maio/Ago. 1998. Disponível em: <https:// rac.anpad.org.br/index.php/rac/article/view/40/40>. Acesso em:
10 Nov. 2018.

VIEIRA, Elias Antônio. Práticas tradicionais e de ecoeficência da indústria de calçados no Brasil. Tempo - Técnica - Território. V.2. No1. 2011.

VIEIRA, E. A.; BARBOSA, A. S. Práticas tradicionais e de ecoeficiência na indústria de calçados no Brasil. Revista Eletrônica: Tempo - Técnica - Território, v.2, 2011. 